\title{
Application of Probabilistic Approach in Reporting Breast Lesions on Fine Needle Aspiration Cytology: Institutional Study
}

\author{
SUNIL VITTHALRAO JAGTAP, ATUL BENIWAL, HEENA PRADEEP SHAH, SWATI SUNIL JAGTAP
}

\section{ABSTRACT}

Introduction: Cancer of breast is among the most common cancer throughout the world. In Indian women rising incidence of breast cancer remains a concern. Due to lack of health awareness and limited breast cancer screening program the majority of these patients are diagnosed at relatively advanced stages. The FNAC becomes first choice of clinicians for the diagnosis of breast lump.

Aim: Present study is aimed to apply probabilistic approach in reporting breast lesions on Fine Needle Aspiration Cytology, its correlation and accuracy study.

Materials and Methods: This was prospective crosssectional study of 188 consecutive patients having palpable breast lump at our institute from period January 2011 to December 2012. FNAC of breast lesions were categorised and histologic correlation was done wherever possible.
Results: The total of 188 patients FNAC was evaluated and correlation with histopathology was done in 109 cases. The cases were categorised depending on the cytomorphological features into 1-6 categories scheme proposed by Wang and Ducatman as positive, suspicious, proliferative with atypia, proliferative without atypia, unremarkable and unsatisfactory.

The probability of finding carcinoma on histopathology for: Positive for carcinoma, suspicious for carcinoma, epithelial proliferative lesion with atypia, epithelial proliferative lesion without atypia, unremarakable and unsatisfactory were, $100 \%, 100 \%, 63.6 \%, 2.6 \%, 0 \%$ and $0 \%$ respectively.

Conclusion: FNAC is widely adopted method for diagnosing breast malignancies. Clinical, imaging and cytopathology examination gives accurate diagnosis of breast carcinoma. The probabilistic approach is easy to apply, uniform method and gives accurate diagnosis in reporting of breast FNAC.

Keywords: Cytological features, Cytomorphological breast, Diagnosis of breast lump

\section{INTRODUCTION}

For rapid diagnosing of breast lump FNAC act as ideal initial diagnostic modality. It is simple safe cost effective and gives rapid reports. So in preoperative assessment of breast masses, the FNAC has become most popular and immensely popular diagnostic procedure. It shows high accuracy, sensitivity and specificity [1,2]. The sensitivity of FNAC in diagnosis of breast lesion is $90-95 \%$ [3]. In various conditions such as hypocellular aspirate, overlapping between benign and malignant lesions like low grade tubular carcinoma, atypical hyperplasia, low grade carcinoma, carcinoma-in-situ, papillary lesions etc., the interpretation is difficult. So many authorities recognised this limitation in finding breast pathology and advised to use probabilistic approach to categorise breast lesions to minimise false negative and false positive results in reporting of breast FNAC National Journal of Laboratory Medicine. 2016 Apr, Vol 5(2): 17-21
[4-6]. This categorisation will help both the cytopathologists and clinicians.

\section{MATERIALS AND METHODS}

This study was a prospective cross-sectional study, done at KIMS University Maharashtra, India, after approval from institutional review and ethical committee. The duration of the study was from January 2011 to December 2012. All the cases presented to our Oncosurgery Department having breast lump were included in the study and the cases with recurrence were excluded from the study. Total 188 patients with palpable breast lump were examined. FNAC was done after taking a written consent from patient. FNAC was performed by pathologist under aseptic condition, using disposable 10ml plastic syringe with 22-23 gauge needles. Smears were stained using Giemsa, Papanicolaou 
and Haematoxylin and Eosin stain. The histopathological examination of surgically excised breast specimens was done using Haematoxylin and Eosin stain. Immunohistochemistry study for ER, PR and HER-2 neu was done on malignant specimens. Cases according to sex, age, site, multicentricity, bilaterality were tabulated. Out of total 188 FNAC cases 109 were correlated with histopathological reports. Of the remaining 79 cases, which were from inflammatory aetiology like mastitis, abscess were medically treated and responded and hence, surgical excision was not done. Also some cases from category of epithelial proliferative lesion without atypia were lost to follow-up. The standard protocol was prepared for each patient for breast pathology reporting. The FNAC smears were categorised into following criteria [4,5].

1) Positive for carcinoma - all four of the following criteria must be met.

a) Cellular dyshesion refers to presence of abundant single epithelial cells or loosely cohesive groups of epithelial cells (this excludes singly bare bipolar cells and stromal cells).

b) Cytologic atypia may be variable but should atleast include high nuclear: cytoplasmic ratio and markedly eccentrically located nuclei. Other useful feature which may or may not be present depending on the level of pleomorphism, include nuclear membrane irregularity, coarse and clumped chromatin, multiple and irregular nucleoli.

c) One cell population refers to one population of atypical epithelial cells, as opposed to mix population of atypical and benign appearing epithelial cells or atypical epithelial cells and stromal cells.

d) Hypercellularity refers to atypical cell population only, rather than increased cellularity due to another component such as inflammatory or stromal cells [6].
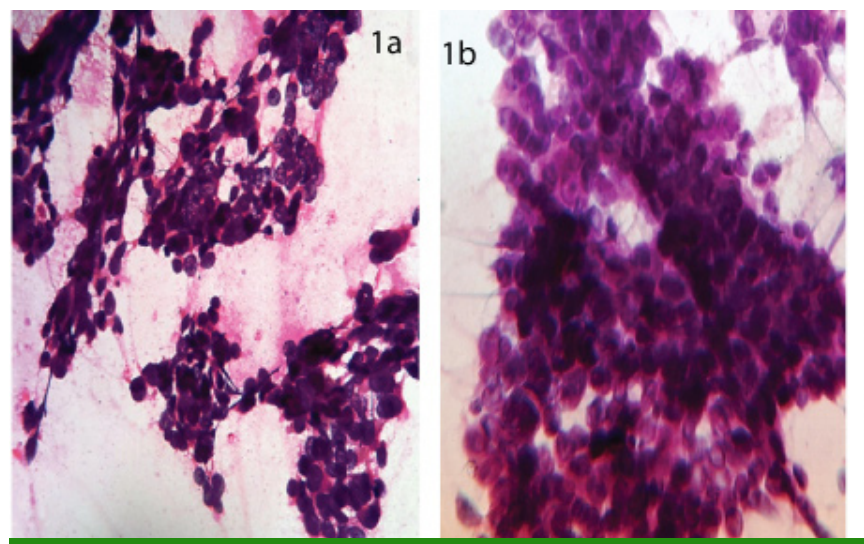

2) Suspicious for carcinoma-When any three of the above features for malignancy are present, a suspicious diagnosis is given [6].

3) Epithelial proliferative lesion (EPL) with atypia-This diagnosis is made when specimen is cellular with many epithelial cells and when epithelial cells present in groups show significant crowding and overlapping and/or specimen show one other feature of malignancy (cellular dyshesion, one cell population, cellular atypia) [6].

4) Epithelial proliferative lesion (EPL) without atypia-This category is used when a specimen is cellular with many epithelial cells and epithelial cells in group show no or mild crowding and overlapping with, obvious myoepithelial cells present. Most fibroadenoma tends to fall in this category [6].

5) Unremarkable-When none of the four features of carcinoma was present, such lesions were described as unremarkable [6].

6) Non diagnostic/unsatisfactory-If specimen is acellular or extremely hypo cellular and when it does not yield an explanation of lesion based on information provided by clinician, it was reported as unsatisfactory [6].

Cyto-histological correlation was done in each category.

The cytological pictures are given in [Table/Fig-1a-1d].

\section{RESULTS}

Out of total 188 patients, 186 (99\%) were females and only 2 (1\%) were male [Table/Fig-2]. 96 (51\%) cases complained lump on left side, 90 (48\%) felt lump on right side and 2 (1\%) patients had lump bilaterally [Table/Fig-3]. Youngest patient was of 16 years of age and oldest was 82 years of age. Maximum number of patients were 52 (27.8\%) from
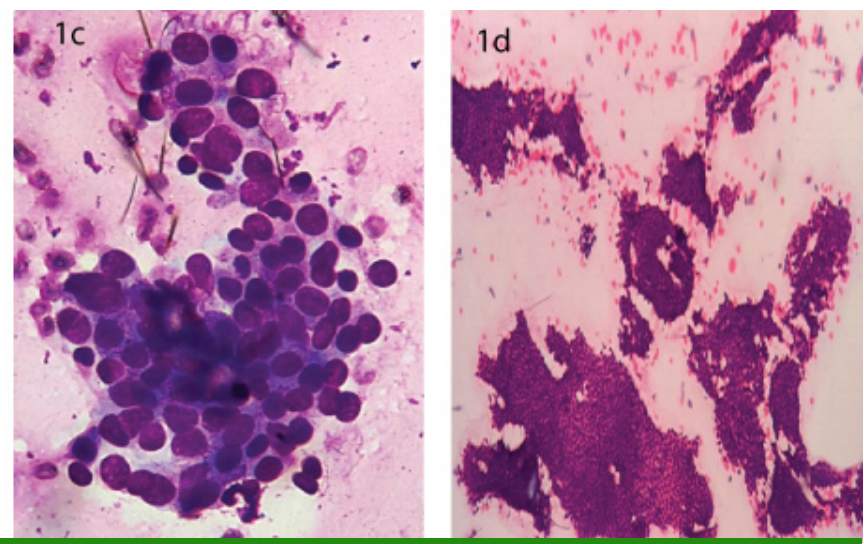

[Table/Fig-1a]: Photomicrograph showing loosely cohesive group of malignant epithelial cells. There is marked nuclear pleomorphism with hyperchromatic nuclei. Positive for carcinoma (H\&E stain 400X) [Table/Fig-1b]: Photomicrograph showing hypercellular smears with atypia, high N/C ratio and pleomorphic nuclei with occasional nucleoli. (H\&E stain, 400X) [Table/Fig-1c]: Photomicrograph showing ductal epithelial cells in cluster. There is mild overcrowding and overlapping of nuclei and some amount of nuclear atypia-EPL with atypia (H\&E stain, X400) [Table/Fig-1d]: Photomicrograph showing bimodal population of ductal epithelial and myoepithelial cells in large clusters without atypia, suggestive of fibroadenoma.(H\&E stain, 100x). 
age group of 41-50 years, followed by 42 (22.3\%) from age group of 31-40 years. Least number of patient were $4(2.1 \%)$ from category of $>70$ years group [Table/Fig-4].

According to the diagnosis on FNAC [Table/Fig-5] maximum number of patients 84 (44.6\%) were put under category of EPL without atypia, followed by 47 (25\%) in category of positive for carcinoma. Eight patients (4.5\%) were diagnosed under category of suspicious for carcinoma whereas, 11 patients (5.8\%) were diagnosed to have EPL with atypia. Rest were either unremarkable or unsatisfactory. Out of 188 cases we received 109 specimens were available for

\begin{tabular}{|l|c|c|}
\hline Sex & Frequency & Percent age \\
\hline Male & 02 & $1 \%$ \\
\hline Female & 186 & $99 \%$ \\
\hline Total & 188 & $100 \%$ \\
\hline
\end{tabular}

[Table/Fig-2]: Showing distribution of cases according to sex

\begin{tabular}{|l|c|c|}
\hline Location & Frequency & Percent age \\
\hline Left & 96 & $51 \%$ \\
\hline Right & 90 & $48 \%$ \\
\hline Bilateral & 02 & $1 \%$ \\
\hline Total & 188 & $100 \%$ \\
\hline
\end{tabular}

[Table/Fig-3]: Showing distribution of cases according to site

\begin{tabular}{|l|c|c|}
\hline Age group & Frequency & Percent age \\
\hline $11-20$ & 12 & $6.4 \%$ \\
\hline $21-30$ & 39 & $20.7 \%$ \\
\hline $31-40$ & 42 & $22.3 \%$ \\
\hline $41-50$ & 52 & $27.8 \%$ \\
\hline $51-60$ & 29 & $15.4 \%$ \\
\hline $61-70$ & 10 & $5.3 \%$ \\
\hline$>70$ & 4 & $2.1 \%$ \\
\hline Total & 188 & $100 \%$ \\
\hline
\end{tabular}

[Table/Fig-4]: Showing distribution of cases according to age histopathology evaluation as modified radical mastectomy, toilet mastectomy or lumpectomy. Out of these 109 cases, maximum number of specimen 42 were from category of positive for carcinoma followed by 39 specimen from category of EPL without atypia [Table/Fig-6].

When applied probabilistic approach to find carcinoma in each category we found $100 \%$ probability of finding carcinoma in; Positive for carcinoma and suspicious for carcinoma category. While $63.6 \%$ and $2.6 \%$ probability was found in EPL with atypia and EPL without atypia respectively. And no case was found positive in unremarkable and unsatisfactory category. There was no false positive case.

\section{DISCUSSION}

The breast carcinoma incidence is continuously on the rise. So in breast lump patient it is essential to establish correct diagnostic procedures, staging of the disease and to detect it in early period. Now a day's clinical examination of breast lump, mammography with FNAC is considered as widely accepted approach for diagnosis of breast lesions. Various studies in literature showed the sensitivity of FNAC

\begin{tabular}{|l|l|l|l|l|}
\hline $\begin{array}{l}\text { Cytology } \\
\text { diagnosis } \\
\text { category }\end{array}$ & Frequency & Percent & $\begin{array}{l}\text { Biopsy } \\
\text { received }\end{array}$ & $\begin{array}{l}\text { Percent } \\
\text { follow-up } \\
\text { on histology }\end{array}$ \\
\hline Positive & 47 & $25 \%$ & 42 & $89.4 \%$ \\
\hline Suspicious & 8 & $4.5 \%$ & 8 & $100 \%$ \\
\hline $\begin{array}{l}\text { EPL with } \\
\text { atypia }\end{array}$ & 11 & $5.8 \%$ & 11 & $100 \%$ \\
\hline $\begin{array}{l}\text { EPL without } \\
\text { atypia }\end{array}$ & 84 & $44.6 \%$ & 39 & $46.4 \%$ \\
\hline Unremarkable & 28 & $14.8 \%$ & 7 & $25 \%$ \\
\hline Unsatisfactory & 10 & $5.3 \%$ & 2 & $20 \%$ \\
\hline Total & 188 & $100 \%$ & 109 & Overall 58\% \\
\hline \\
[Table/Fig-5]: Showing frequency of cases on FNAC and their \\
follow-up. \\
EPL=epithelial proliferative lesion
\end{tabular}

\begin{tabular}{|c|c|c|c|c|c|}
\hline \multicolumn{6}{|c|}{ Applying probabilistic approach between FNAC diagnosis and finding carcinoma on histology in each of six cytology categories } \\
\hline \multirow{2}{*}{$\begin{array}{l}\text { Cytology } \\
\text { diagnosis }\end{array}$} & \multicolumn{3}{|c|}{ Histology diagnosis } & \multirow[t]{2}{*}{ Total } & \multirow{2}{*}{$\begin{array}{c}\text { Probability of } \\
\text { finding carcinoma }\end{array}$} \\
\hline & Positive & DCIS & Benign & & \\
\hline Positive for carcinoma & 42 & 0 & 0 & 42 & $100 \%$ \\
\hline Suspicious for carcinoma & 8 & 0 & 0 & 8 & $100 \%$ \\
\hline EPL with atypia & 7 & 0 & 4 & 11 & $63.6 \%$ \\
\hline EPL without atypia & 0 & 1 & 38 & 39 & $2.6 \%$ \\
\hline Unremarkable & 0 & 0 & 7 & 7 & $0 \%$ \\
\hline Unsatisfactory & 0 & 0 & 2 & 2 & $0 \%$ \\
\hline
\end{tabular}


in diagnosis of breast lesion is $90-95 \%[7,8]$. If there is no disagreement on triple diagnosis, the clinician can give definite treatment based on cytological diagnosis without histopathological confirmation [9]. Therefore a uniform terminology and reporting system with high reproducibility should be used in breast FNAC reporting.

Various criteria are recommended for classification of breast FNAC. National cancer Institute Conference 1996 recommends five categories as benign, atypical, suspicious, malignant and unsatisfactory [10]. Wang and Ducatman [4], Ayata $\mathrm{G}$ et al., [5], criteria was used in our study to categorise breast cytomorphological features as these are reproducible, reduces subjectivity and useful for quality control procedures [11].

In our study all lesions from cytologically diagnosed as positive for carcinoma category were malignant on histopathological report, thus showing $100 \%$ sensitivity and 100\% accuracy. Similar findings were noted by Rupam $T U$ et al., [12]. The probability of finding carcinoma on histopathology for suspicious for carcinoma category was 100\%. For epithelial proliferative lesion with atypia probability was $63.6 \%$. In this category there were seven cases out of 11 which came out to be positive for carcinoma. Two cases out of 7 were lobular carcinoma, three were papillary carcinoma, one was DCIS with micro invasive foci, one was adenoid cystic carcinoma. It shows that cytological atypical features are clinically significant which rises possibility of breast cancer $[4,13]$. FNAC of lobular hyperplasia and invasive lobular carcinoma is associated with high rate of false negative and equivocal diagnosis [14].

The percentage of lesion of suspicious for carcinoma on cytology with malignant on histopathology were $84 \%$ in study of Ayata G et al.,[5], 93\% by Wang H et al.,[4] [Table/ Fig-7] represent a brief comparision between the histological finding compared to other similar studies.

This study showed $97.4 \%$ accuracy in lesion of epithelial proliferative lesion without atypia. One case out of 39 cases

\begin{tabular}{|l|c|c|}
\hline Study & $\begin{array}{c}\text { \% of malignancy } \\
\text { in suspicious } \\
\text { category }\end{array}$ & $\begin{array}{c}\% \text { of malignancy in } \\
\text { epithelial proliferative } \\
\text { lesion with atypia }\end{array}$ \\
\hline Wang et al., [4] & 93 & 36 \\
\hline Ayata et al., [5] & 84 & 27 \\
\hline Panjvani et al., [15] & 100 & - \\
\hline Pandya et al., [16] & 94 & 75 \\
\hline Lim et al., [13] & - & 37 \\
\hline Present study & 100 & 63.6 \\
\hline \\
[Table/Fig-7]: Comparison of percentage of malignancy on histopathology \\
in suspicious category in the categories of suspicious and epithelial \\
proliferative lesion with atypia with various other studies.
\end{tabular}

in his category was found to be DCIS. In unremarkable/ unsatisfactory categories correlation was $100 \%$. No positive case for carcinoma was detected in these two categories on histopathology. Out of 10 cases of unsatisfactory smears, two specimens were available for histolpathological correalation, one showed fibroadenoma and one showed benign phyllodes tumor. Whereas out of 28 cases of unremarkable, seven were available for histopathological correlation, two were gynaecomastia, three were mastitis and two came out to be fibroadenoma. The study by Panjvani $S$ et al., [15], Pandya A et al., [16] were correlated with our study.

In the category of epithelial proliferative lesion with atypia remains the gray zone due to overlapping features on benign epithelial proliferative lesions mainly fibroadenoma and low grade well differentiated carcinoma $[3,17]$. Also cases of sclerosis adenosis, tubular adenoma/carcinoma, proliferative fibrocystic diseases of breast etc should be properly looked for any evidence of malignant change. When uncertainty about diagnosis in such cases is noted, it has to be evaluated further by core biopsy, frozen section and histopathological study.

\section{LIMITATIONS}

As our centre is a tertiary care hospital, most of the patients in this area are from rural population who present with advanced disease stage. Thus, the limitation in the present study was lack of health education, causing loss of follow up of patients with small lesions of benign breast lumps.

\section{CONCLUSION}

Application of probabilistic approach is easy to apply, accurate and uniform to categorise the breast lesions for FNAC reporting. This scheme of definite criteria for reporting FNA results according to the probability of diagnosing breast carcinoma provides a rational basis to guide in management of cases.

\section{REFERENCES}

[1] Rubin M, Horiuchi K, Joy N, et al. Use of fine needle aspiration for solid breast lesions is accurate and cost-effective. Am J of Surg. 1997; 174(6):694-98.

[2] Smith SD, Cason Z, Cabaniss DF, et al. Accuracy of fine needle aspiration biopsy of the breast. Biomedical Sciences Instrumentation. 1997; 33:286-89.

[3] Karin Lindholm - Breast. Orell SR, Sterett GF, Whitakar D. In: Fine needle aspiration cytology. $4^{\text {th }}$ edition, Reed Elsevier India Pvt Ltd, New Delhi. 2005; 167.

[4] Wang HH, Ducatman BS. Fine needle aspiration of breast: A probabilistic approach to diagnosis of carcinoma. Acta Cytol. 1998; 42(2):285-89.

[5] Ayata G, Abu Jawdeh GM, Fraser Jl, et al. Accuracy a consistency in application of a probabilistic approach to reporting breast fine needle aspiration. Acta Cytol. 2003, 47(6):973-78.

[6] Macintosh RF, Merrimen JL, Barnes PJ. Application of the probabilistic approach to reporting breast fine needle aspiration in males. Acta Cytol. 2008; 52:530-34.

National Journal of Laboratory Medicine. 2016 Apr. Vol 5(2): 17-21 
[7] Challa VR, Guru B, Rangappa P et al. Cytological and pathological correlation of fine needle aspiration cytology in assessing breast lumps and axillary node swelling in public sector hospital in India. Pathology Research International. 2013:1-6.

[8] Jethwani DP, Purohit TM, Purohit MB, et al. Accuracy of fine needle aspiration in female breast lesions. Int $\mathrm{J}$ Clin and Biomed Res. 2015; 1(2):37-42.

[9] Morris KT, Stevens JS, Pommier RF et al. Usefulness of the triple test score for palpable breast masses. Archv of Surg. 2001; 136 (9): 1008-12.

[10] The uniform approach to breast fine needle aspiration biopsy. National Cancer Institute fine needle aspiration of breast workshop subcommittees. Diagn Cytopathol. 1997; 16(4); 295311.

[11] Feoli F, Paesmans M, Van Eeckhout P. Fine needle aspiration cytology of breast: impact of experience on accuracy using standard cytological criteria. Acta Cytol. 2008; 52:145-51.
[12] Rupam TU, Choudhary T, Banu SG. Study of fine needle aspiration cytology of breast lump: co-relation of cytologically malignant cases with their histologic findings. BSMM University Joural. 2011; 4(2):60-64.

[13] Lim JC, Al-Masri H, Salhadar A. The significance of diagnosis of atypia in breast FNA. Diagn Cytopathol. 2004; 31(5):285-88.

[14] Hwon S, luffe O, Lee I, et al. Cytologic diagnosis of invasive lobular carcinoma: factors associated with negative and equivocal diagnosis. Diagn Cytopathol. 2004; 31(2):87-93.

[15] Panjvani S, Parikh B, Parikh S et al. Utility of fine needle aspiration cytology in the evaluation of breast lesions. J Clin Diagn Res. 2013;7(12):2777-79.

[16] Pandya A, Shah N. Breast Fine needle aspiration cytology reporting: a study of application of probabilistic approach. Ind Med Gazette. 2013; 54-59.

[17] Ozkara SK, Ustun MO, Paksoy N. The grey zone in breast FNAC. How to repeat it? Acta Cytol. 2002; 46(3):513-18.

\section{AUTHOR(S):}

1. Dr. Sunil Vitthalrao Jagtap

2. Dr. Atul Beniwal

3. Dr. Heena Pradeep Shah

4. Dr. Swati Sunil Jagtap

\section{PARTICULARS OF CONTRIBUTORS:}

1. Professor, Department of Pathology, KIMSU, Karad, Maharashtra, India.

2. Assistant Lecturer, Department of Pathology, KIMSU, Karad, Maharashtra, India.

3. Assistant Lecturer, Department of Pathology, KIMSU, Karad, Maharashtra, India.
4. Associate Professor, Department of Physiology, KIMSU, Karad, Maharashtra, India.

\section{NAME, ADDRESS, E-MAIL ID OF THE CORRESPONDING AUTHOR:}

Dr. Sunil Vitthalrao Jagtap, Professor, Department of Pathology, Krishna Institute of Medical Sciences, Karad-415539, Maharashtra, India.

E-mail: drsvjagtap@gmail.com

FINANCIAL OR OTHER COMPETING INTERESTS: None.

Date of Publishing: Apr 01, 2016 